Commentary on The Case of Ms. Q: A Demonstration of Integrative Psychotherapy Guided by "Core Clinical Hypotheses"

\title{
“A New Therapy for Each Patient”: Integrative Case Formulation and Treatment in the Case of Ms. Q
}

\author{
LISA D. GRINFELD ${ }^{\mathrm{a}, \mathrm{b}}$ \\ a Graduate School of Applied and Professional Psychology, Rutgers University \\ b Correspondence concerning this article should be addressed to: Lisa Grinfeld, Graduate School of Applied and Professional \\ Psychology, Rutgers University, 152 Frelinghuysen Road, Piscataway, NJ 08854, USA. \\ Email: lgrinfel@eden.rutgers.edu
}

\begin{abstract}
Ingram's (2009) case history of Ms. Q demonstrates how an integrative model can be used to tailor the treatment approach to the individual client. Ms. Q is a married mother in her midthirties who seeks help for difficulties balancing career goals and family relationships, whose only diagnoses fall under DSM-IV V-Code categories. This commentary focuses on issues salient to clinicians in training, including (a) the pressure to choose a theoretical orientation, (b) the complexities of choosing a treatment approach for any individual client, and (c) the relationship between discrete symptoms and general problems of living. I also address Ingram's (2009) case formulation and treatment model in the context of current theories of psychotherapy integration.
\end{abstract}

Keywords: integrative psychotherapy; technical eclecticism; assimilative integration; case formulation; client treatment matching; clinical psychology graduate training

"The therapist must strive to create a new therapy for each patient."

-Irvin Yalom, The Gift of Therapy: An Open Letter to a New Generation of Therapists and Their Patients

\section{A GRADUATE STUDENT PERSPECTIVE ON THE GUIDING CONCEPTION}

As a graduate student committed to psychotherapy integration, I was delighted to read Dr. Ingram's (2009) case study of Ms. Q, a woman in her mid-thirties who comes to treatment because she is having difficulty making decisions about career and family. What is so novel about Ingram's approach is that she incorporates theories and techniques from a wide variety of perspectives, but does so in a thoughtful and systematic way. 
Ingram presents the guiding conception for her case formulation model in the context of her own graduate training, in which she "resisted pressure to 'choose an orientation,"” believing instead that "every client deserves a unique, personalized treatment plan” (p. 3). Ingram argues that "rather than facing a new client with a treatment strategy in mind, the therapist should learn about the unique client and develop a case formulation that draws from ideas from the entire range of available models of human functioning and change” (p. 3). This rationale for integrated treatment resonates with me, because I have always felt that our priority as clinicians is to help alleviate our clients' distress using whatever techniques we have available in our repertoire, rather than rejecting techniques because they don't “fit” our chosen theoretical orientation.

Surprisingly, the culture of training in psychology rarely supports an integrationist or multi-faceted perspective. As an undergraduate, I remember being told on the first day of Introduction to Psychology that there would be absolutely no exposure to Freud's theories, and any student interested in Freud should take classes in the Literature Department instead. When applying to graduate school, I found that the schools to which I applied either expected students to have already decided on a theoretical orientation, or to choose an advisor who would mentor the student in a particular theoretical orientation, such that the student would become socialized into the advisor's point of view. Even at training programs like Rutgers University's Graduate School of Applied and Professional Psychology, where students like myself are required to take courses in a variety of theoretical orientations, students generally adhere to one orientation or another, perhaps due to philosophical inclinations (Messer \& Winokur, 1980), or because it is difficult not to define oneself in relation to an opposing perspective (Safran \& Messer, 1997).

What is appealing about Ingram's approach is that it arose out of a felt need to help graduate students navigate the current educational atmosphere in which reification of theory is the norm, recognizing that students often become frustrated when faced with a client who does not quite fit (or worse, "resists") the treatment the clinician is supposed to be providing. Those clients who arrive in a psychodynamic therapy wanting structure, skills, and education are usually pressured to "tolerate ambiguity," while those who arrive in cognitive-behavioral therapy wanting to "just talk" about their problems are seen as needing increased motivation and persistent redirection toward goals. As the case of Ms. Q illustrates, Ingram's integrative model addresses these issues by choosing interventions based on the client's stated problems and goals, and then monitoring responses to interventions so that those that the client does not find helpful can be abandoned while those that resonate are pursued. This type of continual dialogue is recommended by Safran and Messer (1997), who propose that negotiation with clients about the tasks and goals of therapy is an important element of psychotherapy integration.

Graduate students like myself want sincerely to be helpful to the clients who have generously agreed to be seen by clinicians-in-training, and we are generally willing to experiment with just about any approach that may be useful and that our supervisors deem appropriate. At the same time, we are exposed to a barrage of conflicting research evidence about what is helpful to clients. We read about the "dodo bird verdict," referring to the finding that all approaches work about the same for most problems (Luborsky et al., 2002; Luborsky, 
Singer \& Luborsky, 1975); the “common factors” included in most therapies that are highly correlated with therapeutic outcome (Grencavage \& Norcross, 1990; Messer \& Wampold, 2002); and evidence that experienced clinicians are not significantly more effective than novice therapists (Christensen \& Jacobson, 1994). Simultaneously, we are encouraged to learn specific, empirically-supported treatments (ESTs) for particular diagnostic problems, since we are warned that in today's climate of managed care, it is our professional responsibility to deliver such ESTs (Chambless \& Ollendick, 2001; Sanderson, 2003) and that by not doing so we risk violating ethical standards or committing malpractice (Peterson, 2004).

In an effort to reconcile the importance of client strengths and preferences (e.g., Bohart \& Tallman, 1999) with empirical evidence, we learn about the American Psychological Association's (APA's) Evidence-Based Practice in Psychology (EBPP) approach, which is "the integration of the best available research with clinical expertise in the context of patient characteristics, culture, and preferences” (APA Presidential Task Force, 2006). Although the stated purpose of EBPP is "to promote effective psychological practice and enhance public health by applying empirically supported principles of psychological assessment, case formulation, therapeutic relationship, and intervention," the APA makes no specific recommendations about how to integrate "research evidence," "clinical expertise," and "patient characteristics” in actual practice (APA Presidential Task Force, 2006). What is so compelling about Ingram's model of case formulation and treatment is that it incorporates the three components of EBPP in a practical context that is accessible to both experienced clinicians and graduate students in training.

\section{TREATMENT OF A “V-CODE” CASE}

I was pleased with Dr. Ingram's choice to present a case study of a woman whose only formal DSM-IV diagnoses fall into the "V-Code" categories of "Partner Relational Problem" and "Occupational Problem." Although these issues are ubiquitous and play a significant role in all therapies, direct treatment of problems having to do with life choices and satisfaction are usually denigrated in favor of treating "symptoms." Thus there is little discussion in graduate training about how to formulate and treat V-Code diagnoses, whether they occur in the context of definite "symptoms" or not.

Perhaps due to the pressures managed care regulations impose on psychologists, graduate training in case formulation tends to focus heavily on some clinical hypotheses while neglecting others. For instance, Ingram's hypotheses about Behavioral and Learning Models (BL), Cognitive Models (C), and Psychodynamic Models (P) are well-covered in the current literature, while Existential and Spiritual Models (ES) and Crisis, Stressful Situations, and Transitions (CS) are not viewed as prominent areas of interest. Thankfully, attention to Social, Cultural and Environmental Factors (SCE) has increased through political action, heightened awareness, and requirements from the APA. When confronted with a Biological Hypothesis (B), however, we are trained to defer to the expertise of psychiatrists by "referring out." 
One of the strengths of Ingram's model is that it provides a comprehensive and structured framework for treating areas of clinical attention that fall under the V-Code categories: relationship, occupational, identity, acculturation, phase-of-life, or spiritual problems. In my own clinical experience, these issues are rarely absent from treatment and appear inextricably connected to symptoms defined under Axis I or Axis II disorders of the DSM-IV. By separating them arbitrarily, as do both the DSM-IV and the empirically-supported treatments that have been developed for DSM-IV disorders (Chambless \& Ollendick, 2001), we omit important aspects of an individual's subjective experience. Using Ingram's 28 Core Clinical Hypotheses, both DSMIV-defined symptoms (e.g., panic, depressed mood, and ruminative thoughts) and DSM-IVdefined V-Code categories can be integrated into a complete formulation that takes into account all potential contributing factors to an individual's distress and functional impairment, which are the criteria used in the DSM-IV to determine the areas that should be the focus of clinical attention (Spitzer \& Wakefield, 1999).

Most notable in Ingram's case study is that Ms. Q arrives in therapy without significant Axis I or Axis II symptoms, but with four identifiable problem areas that are highly distressing and are beginning to result in functional impairment: (1) not being able to engage in creative writing as much as she would like, (2) a tendency to leave difficult situations impulsively, (3) neglecting her own needs to attend to others' needs, and (4) uncertainty about whether or not she would like to stay married (pp. 9-10). The resolution of these issues involves "intermittent" treatment over two years and four months, as Ingram attends to issues that are salient to the client using strategies determined by the application of the 28 Core Clinical Hypotheses.

Ingram's case study of Ms. Q demonstrates the importance of having a flexible method for informed decision-making when helping clients manage the distress surrounding life and relationship issues. Despite the undervaluation of V-Code issues in empirical research and literature, these problems are often identified by clients as requiring the most attention in the clinical setting. By the end of the treatment, Ms. Q does not report a reduction in symptoms, but "a new awareness of having a 'solid strong core," " different from the "'crazy hysterical out of control self' that she used to fear was her core” (p. 22). Whereas another treatment approach might have focused on Ms. Q’s occasional, “symptoms of anxiety and dysphoria” (p. 11), Ingram's active integrative treatment allows Ms. Q to develop a revised "core” self, one that is now able to make decisions in a way that feels satisfying and authentic. To me, this is a better outcome than the short-term reduction of symptoms, in that Ms. Q appears to have gained the ability to understand and perhaps prevent such difficulties in the future.

\section{INGRAM'S MODEL IN THE CONTEXT OF THEORIES OF PSYCHOTHERAPY INTEGRATION}

Within the study of psychotherapy integration, a major debate concerns the extent to which theories of integration can be translated into practice (Lampropoulos, 2001). While technical eclecticism "advocates selectively combining the best techniques, regardless of their theoretical origin, and applies them in such a way as to maximize the therapeutic results" 
(Lampropoulos, 2001), critics of technical eclecticism argue that simply importing techniques changes their meaning, with potentially negative effects for both the efficacy of the technique and the therapeutic alliance (Messer, 2001).

As an alternative, Messer (2001) suggests the model of assimilative integration, in which the therapist establishes a "home base" theory and then "assimilates" techniques into the treatment, paying careful attention to the coherence of the technique within the home base theory (Lampropoulos, 2001; Messer, 2001). The aim of assimilative integration is to prevent "a meaningless, contradictory hodgepodge that will be useless or even harmful in practice" and to allow clinicians to develop a professional identity within one orientation without having to reject potentially useful techniques from other traditions (Lampropoulos, 2001).

Ingram’s model, which includes 28 Core Clinical Hypotheses from seven different theoretical perspectives, is more technically eclectic than assimilative, and yet there is little evidence from the case study of Ms. Q that Ingram's interventions are useless or harmful to the client. For instance, Ingram's intervention using the theory of “parts” (Psychodynamic Models) resonates with the client's sense that she has conflicting feelings, and some of her "thinking parts” turn out to have maladaptive cognitive schemas (Cognitive Models) (17). As part of Ingram's initial formulation and treatment plan, Ingram hypothesizes that Ms. Q has been kept from experiencing painful emotions due to both emotional conditioning (Behavioral and Learning Models) and defense mechanisms (Psychodynamic Models), a theoretically contradictory conjecture but one that appears to accurately capture the client's experience.

One argument for assimilative integration over technical eclecticism is the possibility that at an underlying philosophical level, different models of psychology are mutually exclusive (Messer \& Winokur, 1980). For example, the cognitive-behavioral therapist's emphasis on action-oriented problem-solving is incompatible with the psychodynamic therapist's emphasis on exploration and tolerance for ambiguity (Messer \& Woolfolk, 1998). Messer \& Winokur (1980) astutely notice that in graduate school, "it does not take long before students sort themselves out as behaviorally or psychodynamically oriented, perhaps because they soon find one approach or the other more compatible with their own views of reality." Professional identity then becomes established along theoretical lines, with deepening commitment to particular theoretical approaches over others (Safran \& Messer, 1997).

A still unanswered question in the psychotherapy literature is whether or not clients themselves are prone to these kinds of theoretical inclinations, and, if so, how these inclinations impact the course of therapy. The case of Ms. Q illustrates a treatment in which the "values, preferences, and interpersonal style” (p. 11) of the client are given substantial weight, as Ingram chooses interventions based upon Ms. Q’s session-by-session focus along with her direct feedback about how the treatment is progressing. Ingram notices that Ms. Q begins to initiate use of the internal parts vocabulary (p. 14), which confirms the "fit" of this approach, but lets go of the idea to use chair work when Ms. Q expresses discomfort with it (p. 14-15). Reading the case study, I wondered how the therapy would have progressed had the client been more inclined 
to focus on Cognitive or Behavioral and Learning Models, and whether Ingram would have chosen commensurate treatment techniques. I could imagine Ms. Q using a pros and cons chart to directly engage the process of making a decision about whether to stay in the marriage, or learning behavioral self-soothing techniques to calm herself during times of emotional stress (e.g., Linehan, 1993).

Whether the therapist or the client initiates treatment choices is an important area of consideration for psychotherapy integration in particular, because different theoretical models contain alternate assumptions about the role of the client in therapy. Ingram's treatment of Ms. Q fits with Bohart \& Tallman's description of the “client as active self-healer," where “it is clients who make therapy work by operating on therapists' interventions” (Bohart \& Tallman, 1999; also see Bohart, 2006). Ingram offers interpretations, psychoeducation, and empathic attunement based upon her assessment of what "fits" the client's moment-to-moment needs, but continually revises her formulations and procedures as she gains more data from the client. One instance of this type of process occurs when Ms. Q accuses Ingram of using cultural stereotypes after Ingram attempts to explore Ms. Q's guilt about leaving her son if she chooses to pursue her writing career (p. 14). Ingram's initial hypothesis is that Ms. Q's beliefs are the result of faulty all-or-nothing thinking (Cognitive Hypothesis), and based on this hypothesis, Ingram attempts to challenge Ms. Q's dysfunctional beliefs by pointing to evidence that she has had some success at pursuing professional goals while maintaining her responsibilities as a mother (p. 14). Ms. Q appears unimpressed by Ingram's intervention, however, and brings to therapy a book about gender differences that leads to an "academic" discussion about, "society, socialization, and social change” (p. 15) —an activity in therapy that is initiated by Ms. Q to communicate to Ingram her preference for viewing the particular issue of balancing career and marriage through the lens of a cultural hypothesis (Social, Cultural, and Environmental Factors).

The benefit of following the client's preference in this case is that it enhances Ingram's working alliance with Ms. Q, a common factor known to be significant for treatment outcomes (e.g., Constantino, 2001). Ms. Q expresses a need—-to explore her conflict between professional goals and responsibilities as a mother through the lens of cultural factors-and this need is met by Ingram, whereas other therapists adhering to a strict theoretical orientation might have redirected Ms. Q towards a theoretically-syntonic activity in the session. Ingram's choice to follow the client's “orientation preference” in this moment seems, therefore, to constitute an empathic attunement to process as well as to content, furthering not just the working alliance but also Ms. Q's sense that her needs can be acknowledged and met. Given that Ms. Q struggles with identifying and asserting her needs to others, Ingram's empathic attunement to process in this session might also be seen as a corrective emotional experience, an event in which affective change takes place through an interaction with the therapist that is different from the client's previous experiences (Alexander \& French, 1946). This type of attunement to psychotherapy process raises questions about how procedures from different theoretical orientations may have significant implications through interaction effects with the client's individual characteristics. 
Ingram's technically-eclectic model is effective in the case of Ms. Q because Ms. Q enters therapy ready to take on the role of an active client who expects her therapist to participate as a collaborative equal. Ms. Q tells Ingram "point blank" that she does not "want to be treated like a 'case' but like a 'real human being,"” noting her disappointment with a prior therapist who left long silences and never offered an opinion (p. 22). Ms. Q also has the strengths of being intelligent, eager to learn, and "genuinely interested in hearing a new perspective” (p. 9). In this particular clinical situation, Ingram can integrate a variety of different approaches without an underlying "home base" orientation (Messer, 1992) because the client values the process of viewing herself from myriad perspectives and trusts her own ability to use interventions that resonate while discarding those that do not.

In general practice, however, clients do not always have such readiness or capacity to enter into a collaborative therapeutic relationship. Clients often look to therapists to be experts on their problems-and to take an authoritative role in deciding which explanation and intervention will be the most beneficial. Consider, for instance, a client who presents in therapy with panic attacks that appear to come out of the blue without connection to external life circumstances. Using the 28 Core Clinical Hypotheses, we might entertain the possibility that the panic attacks have an underlying medical cause (Biological Models), are a conditioned response to environmental cues (Behavioral and Learning Models), are perpetuated by distorted cognitions (Cognitive Models), or are related to underlying fears and anxieties (Psychodynamic Models). How any particular therapist might choose to explain to such a client the cause of the panic attacks and the rationale for a subsequent treatment approach will depend on (1) the theoretical orientation of the clinician, (2) the therapist's knowledge of empirically-supported treatment for panic attacks (Chambless \& Ollendick, 2001), and (3) the therapist's prior experience treating panic attacks in similar clients. Without direct feedback from the client about which hypotheses resonate and which do not, the therapist must assume greater responsibility for providing a clear rationale for treatment procedures. In Ingram's model, it is uncertain how she would test the accuracy of any one hypothesis, since clinical decisions depend on "goodness-of-fit" (p. 6) with information provided from the client as well as whether or not the client's problems remit. Additionally, as the hypotheses presented in Ingram's model proliferate, a client who is oriented towards straightforward explanations may feel increased anxiety, with the potential to view the therapist as unprofessional or lacking expertise.

\section{THOUGHTS ON THE 28 CORE CLINICAL HYPOTHESES}

Reading the case of Ms. Q, I am struck by how well Ingram's 28 Core Clinical Hypotheses capture the highlights of most major theoretical models of psychology. By including hypotheses from seven different clinical perspectives-Biological; Crisis, Stressful Situations, and Transitions; Behavioral and Learning; Cognitive; Existential and Spiritual; Psychodynamic; and Social, Cultural and Environmental-Ingram encourages the clinician to attend to a greater variety of explanations than would usually be considered. This is an advantage in clinical practice, since by omitting a particular perspective we limit our access to different facets of a client's experience. 
A major event in Ms. Q's therapy occurs when she chooses to focus on the decision to leave her family. For this problem, Ingram needs the Existential and Spiritual hypotheses that describe the freedom and autonomy of adulthood and the responsibility for choices and consequences. Without a clear formulation of Ms. Q's quandary based on underlying theory, Ingram could not have proceeded with her intervention, which involves reminding Ms. Q of the consequences of her decision and self-disclosing in order to accentuate the potential consequences if Ms. Q chose to leave. The effect of this intervention is that Ms. Q develops greater empathy for her family, and eventually feels that she has gained "an understanding of all the pros and cons of either choice... relatively free of self-deceptive rationalizations” (p. 18). By emphasizing the existential and spiritual framework at this therapeutic choice-point, Ingram offers Ms. Q the satisfaction of feeling able to make a decision with autonomy, an outcome not as directly addressed in other theoretical approaches like the Cognitive Model (Safran \& Messer, 1997). This kind of intervention highlights the importance of having a variety of theoretical models from which to choose, as each decision has implications for which part of the client's experience it may capture and address. Unfortunately, the 28 Core Clinical Hypotheses leave out several well-established approaches that have been shown to be effective in therapy. For instance, ideas such as transference and countertransference, attachment theory, and acceptancebased therapy (e.g., Hayes’ [2004] Acceptance and Commitment Therapy and Linehan’s [1993] Dialectical Behavior Therapy) are omitted from the 28 Core Clinical Hypotheses, although they are widely used in practice.

One noteworthy aspect of the way in which Ingram applies the 28 Core Clinical Hypotheses is that she often refers to various theorists whose ideas seem to resonate with Ms. Q's particular issue. Having been trained in self psychology, Ingram focuses on Kohut's concept of "selfobject" and employs this concept to help Ms. Q understand how she uses others and how others use her to meet their emotional needs. When Ms. Q begins to describe feeling responsible for her mother's emotions, Ingram incorporates concepts from Alice Miller's The Drama of the Gifted Child to explain to Ms. Q her early relationship with her mother (p. 19). Ingram also refers to the theories of Murray Bowen, Eugene Gendlin, and Aaron Beck at different points in the therapy depending on which aspects of Ms. Q’s presentation are most salient at the time (pp. 15, 17).

These moments suggest that Ingram's use of 28 Core Clinical Hypotheses may be best applied as an inductive, rather than a deductive model. In other words, once a clinician has a fund of knowledge about various theoretical approaches, the 28 Core Clinical Hypotheses can be used to synthesize the information already known by the clinician. However, if Ingram's approach were to be taught deductively, it risks lacking the significant depth of information needed to truly be able to call to mind an appropriate intervention at an appropriate moment. In essence, the 28 Core Clinical Hypotheses are heuristics that stand in for generally complex theories and ideas that have been worked through by experts in the respective fields. Taking one Core Clinical Hypothesis as an example, the P1 hypothesis which says that "the problem is explained in terms of Internal Parts and Subpersonalities that need to be heard, understood, and coordinated,” briefly describes an entire body of psychodynamic literature on parts, self-states, 
and the integration of self (e.g., Bromberg, 1998; Howell, 2005). Although Ingram’s (2006) 696-page book, Clinical Case Formulations: Matching the Integrative Treatment Plan to the Client, is an heroic attempt to flesh out the 28 Core Clinical Hypotheses, including descriptions of major theories and lists of references, only rigorous clinical training can cover the intricacy of the theories to which the 28 Core Clinical Hypotheses refer.

I also wonder about the implications of learning the 28 Core Clinical Hypotheses in the context of an integrative model, rather than receiving instruction in various models in their original contexts. Discussing clinical training, Safran \& Messer (1997) argue that "in the same way that one has to spend time in other cultures in order to truly understand them, one has to immerse oneself in other therapeutic orientations in order to be able to appreciate their strengths and recognize their limitations.” The reasoning behind this approach comes from the postmodern idea of contextualism, which argues that meaning is assigned within contexts, and that removing an idea from its context necessarily involves a change in meaning (Safran \& Messer, 1997). By removing clinical hypotheses and techniques from their original contexts, Ingram's model may forfeit some useful and efficacious aspects of each treatment approach. With an inductive rather than a deductive use of Ingram's model, however, clinicians would be able to first learn a variety of treatment approaches in their original contexts and then coordinate them using Ingram's 28 Core Clinical Hypotheses and case formulation techniques.

\section{TOWARDS INTEGRATION AS A THEORETICAL ORIENTATION}

From my own experience as a graduate student, Dr. Ingram is absolutely correct that beginning clinicians are hungry for a structured model that allows integration of a variety of theories in a way that allows flexibility and "goodness of fit" with the client's presentation, while at the same time minimizing the "haphazard, arbitrary, and idiosyncratic" nature of some forms of eclecticism (Lampropoulos, 2001). Early clinicians are also invested in developing a professional identity, but some, like Ingram, resist pressure to “'choose an orientation”” (p. 3) and instead prefer to let the client's individual characteristics and preferences lead the way. In this sense, Ingram's model provides graduate students the opportunity not only to pursue psychotherapy integration within a structured and practiced framework, but also to pursue identities as "integrationally-oriented” therapists.

\section{REFERENCES}

Alexander, F. \& French, T. M. (1946). Psychoanalytic therapy: Principles and application. New York: Ronald Press.

APA Presidential Task Force on Evidence-Based Practice (2006). Evidence-based practice in psychology. American Psychologist, 61, 271-285.

Bohart, A.C. (2006). The client as active self-healer. In G. Stricker \& J. Gold (Eds.), A casebook of psychotherapy integration. Washington, D.C.: American Psychological Association.

Bohart, A.C. \& Tallman, K. (1999) How clients make therapy work: The process of active selfhealing. Washington, D.C.: American Psychological Association. 
Bromberg, P.M. (1998). Standing in the spaces: Essays on clinical process, trauma, and dissociation. Mahwah, NJ: Analytic Press.

Chambless, D.L. \& Ollendick, T.H. (2001). Empirically supported psychological interventions: Controversies and evidence. Annual Review of Psychology, 52, 685-716.

Christensen, A. \& Jacobson, N.S. (1994). Who (or what) can do psychotherapy: The status and challenge of nonprofessional therapies. Psychological Science, 5, 9-13.

Constantino, M.J., Castonguay, L.G., \& Schut, A.J. (2001). The working alliance: A flagship for the scientist-practitioner model in psychotherapy. In G. Shick Tryon (Ed.), Counseling based on process research. New York: Allyn \& Bacon.

Grencavage, L.M. \& Norcross, J.C. (1990). Where are the commonalities among the therapeutic common factors? Professional Psychology: Research and Practice, 21, 372-378.

Hayes, S.C. (2004). Acceptance and commitment therapy, relational frame theory, and the third wave of behavioral and cognitive therapies. Behavior Therapy, 35, 639-665.

Howell, E. (2005). The dissociative mind. Mahwah, NJ: Analytic Press.

Ingram, B.L. (2006). Clinical case formulations: Matching the integrative treatment plan to the client. Hoboken, NJ: John Wiley \& Sons, Inc.

Ingram, B.L. (2009). The case of Ms. Q: A demonstration of integrative psychotherapy guided by “core clinical hypotheses." Pragmatic Case Studies in Psychotherapy, Vol. 5(1), Article 1, 1-42. Available: http://hdl.rutgers.edu/1782.1/pcsp_journal.

Lampropoulos, G.K. (2001). Bridging technical eclecticism and theoretical integration: Assimilative integration. Journal of Psychotherapy Integration, 1, 5-18.

Linehan, M.M. (1993). Skills training manual for treating borderline personality disorder. New York: The Guildford Press.

Luborsky, L., Rosental, R., Diguer, L., Andrusyna, T.P., Berman, J.S., Levitt, J.T., Seligman, D.A., \& Krause, E.D. (2002). The dodo bird verdict is alive and well-mostly. Clinical Psychology: Science and Practice, 9, 2-12.

Luborsky, L., Singer, B., \& Luborsky, L. (1975). Comparative studies of psychotherapies: Is it true that "Everyone has won and all must have prizes"? Archives of General Psychiatry, 32, 995-1008.

Messer, S.B. (1992). A critical examination of belief structures in integrative and eclectic psychotherapy. In J.S. Norcross \& M.R. Goldfried (Eds.), Handbook of Psychotherapy Integration. New York: Basic Books.

Messer, S.B. (2001). Introduction to the special issue on assimilative integration. Journal of Psychotherapy Integration, 11, 1-4.

Messer, S.B. \& Wampold, B.E. (2002). Let’s face facts: Common factors are more potent than specific therapy ingredients. Clinical Psychology: Science and Practice, 9, 21-25.

Messer, S.B. \& Winokur, M. (1980). Some limits to the integration of psychoanalytic and behavior therapy. American Psychologist, 35, 818-827.

Messer, S.B. \& Woolfolk, R.(1998). Philosophical issues in psychotherapy. Clinical Psychology: Science and Practice, 5, 251-263.

Peterson, D.R. (2004). Science, scientism, and professional responsibility. Clinical Psychology: Science and Practice, 11, 196-210. 
Pragmatic Case Studies in Psychotherapy, http://pcsp.libraries.rutgers.edu

Volume 5, Module 1, Article 4, pp. 58-68, 04-06-09 [copyright by author]

Safran, J.D. \& Messer, S. B. (1997). Psychotherapy integration: A postmodern critique. Clinical Psychology: Science and Practice, 4, 140-152.

Sanderson, W.C. (2003). Why empirically supported psychological treatments are important. Behavior Modification, 27, 290-299.

Spitzer, R.L. \& Wakefield, J.C. (1999). DSM-IV diagnostic criterion for clinical significance: Does it help solve the false positives problem? American Journal of Psychiatry, 156, 1856-1864.

Yalom, I. (2002). The gift of therapy: An open letter to a new generation of therapists and their patients. New York: HarperCollins. 